Article

\title{
Rubber Dam Isolation and High-Volume Suction Reduce Ultrafine Dental Aerosol Particles: An Experiment in a Simulated Patient
}

\author{
Julián Balanta-Melo ${ }^{1,2, * \mathbb{C}}$, Albio Gutiérrez ${ }^{3}$, Gustavo Sinisterra ${ }^{1}$, María del Mar Díaz-Posso ${ }^{1}$, \\ David Gallego ${ }^{1}$, Judy Villavicencio ${ }^{1}$ and Adolfo Contreras ${ }^{1}$ \\ 1 School of Dentistry, Faculty of Health, Universidad del Valle, Cali 760043, Colombia; \\ gustavo.sinisterra@correounivalle.edu.co (G.S.); maria.mar.diaz@correounivalle.edu.co (M.d.M.D.-P.); \\ dmgu03@gmail.com (D.G.); judy.villavicencio@correounivalle.edu.co (J.V.); \\ adolfo.contreras@correounivalle.edu.co (A.C.) \\ 2 Evidence-Based Practice Unit Univalle, Hospital Universitario del Valle, Cali 760043, Colombia \\ 3 Research Group in Fatigue and Surfaces, Mechanical Engineering Department, Universidad del Valle, \\ Cali 760032, Colombia; albio.gutierrez@correounivalle.edu.co \\ * Correspondence: julian.balanta@correounivalle.edu.co
}

Received: 26 August 2020; Accepted: 8 September 2020; Published: 11 September 2020

Featured Application: This work contains relevant data for advanced simulation analysis such as computational fluid dynamics (CFD) that help to understand and mitigate dental aerosol particles towards a safe clinical environment.

\begin{abstract}
The ongoing Coronavirus Disease 2019 (COVID-19) pandemic has triggered the paralysis of dental services ascribed to the potential spread of severe acute respiratory syndrome (SARS)-CoV-2. Aerosol-generating procedures (AGPs) are common in dentistry, which in turn increase the risk of infection of the dental personnel due to the salivary presence of SARS-CoV-2 in COVID-19 patients. The use of rubber dam isolation (RDI) and high-volume evacuators (HVE) during AGPs is recommended to control dental aerosols, but the evidence about their effectiveness is scarce. This first study aimed to compare, in a simulated patient, the effectiveness of the following strategies: standard suction (SS), RDI and RDI + HVE. Using the laser diffraction technique, the effect of each condition on the volume distribution, average size and concentration of coarse $\left(\mathrm{PM}_{10}\right)$, fine $\left(\mathrm{PM}_{2.5}\right)$ and ultrafine $\left(\mathrm{PM}_{0.1}\right)$ particles were evaluated. During the teeth drilling, the highest volume fraction of dental aerosol particles with SS was below $1 \mu \mathrm{m}$ of aerodynamic diameter. Additionally, the RDI + HVE significantly reduced both the ultrafine dental aerosol particles and the concentration of total particulate matter. AGPs represent a potential risk for airborne infections in dentistry. Taken together, these preliminary results suggest that isolation and high-volume suction are effective to reduce ultrafine dental aerosol particles.
\end{abstract}

Keywords: aerosol-generating procedures; airborne particulate matter; dental simulator; high-speed handpiece; ultrafine

\section{Introduction}

The ongoing Coronavirus Disease 2019 (COVID-19) pandemic has triggered several forms of collateral damage but one obvious effect is the paralysis of dental services caused by the potential spread of severe acute respiratory syndrome (SARS)-CoV-2 [1]. In dentistry, approaches such as preventive, restorative and surgical use water-cooled rotary devices (i.e., high-speed handpieces) to perform interventions that are considered aerosol-generating procedures (AGPs) [2-4]. Taking into account 
that the SARS-CoV-2 viral load is high at saliva, nose and oropharyngeal secretions in COVID-19 patients $[5,6]$, other patients and dental personnel are considered at high risk for cross-infection spreading [7]. Recommendations have been released oriented to reopen dental practice and mitigate the risk of AGPs $[3,4,8,9]$ that include the use of rubber dam isolation (RDI) and high-volume evacuators (HVE) for dental procedures [3,7,10-12]. However, there is a lack of evidence that supports the effectiveness of RDI and HVE, either alone or combined, to control dental aerosols during dental restorative procedures [4,13-15].

Dental aerosols contain potentially hazardous particulate matter of submicron size. Restorative dental procedures such as tooth grinding produce particulate matter (PM) that exhibit a high proportion of particles with an aerodynamic diameter smaller than $10 \mu \mathrm{m}\left(\mathrm{PM}_{10}\right)[16,17]$. Aerosolized particles, based on the size below each name, are defined as coarse $\left(\mathrm{PM}_{10}\right)$ and fine $\left(\mathrm{PM}_{2.5}\right)$ particles [18]. After reaching the lower respiratory airways, the $\mathrm{PM}_{2.5}$ are associated with systemic inflammation and increased respiratory mortality risk [19-21]. A significant correlation was found between new COVID-19 cases and the average amount of outdoor coarse particles in cities from China and Italy [22,23]. Viral RNA was detected in samples taken after coughing in influenza positives from particles with an aerodynamic diameter smaller than one micron $\left(\mathrm{PM}_{1}\right)$, which correspond to a fraction of the $\mathrm{PM}_{2.5}$, [24]. In a similar fashion, the SARS-CoV-2 RNA was also detected in $\mathrm{PM}_{2.5}$ from aerosol-coated areas of two hospitals from Wuhan [25]. Ultrafine particles $\left(\mathrm{PM}_{0.1}\right)$, another fraction of $\mathrm{PM}_{2.5}$, also known as nanoparticles, are also associated with health risks, including also systemic inflammation and cancer [26]. However, there is a lack of published evidence regarding the control of fine and ultrafine particles using mitigation strategies in dentistry. Inasmuch as PM includes fine and ultrafine particles that are associated with AGPs in dental settings, it is relevant to understand its behaviour and determine the potential risk of airborne infections during dental practice $[7,16,27]$. In this first study, the authors test the effectiveness of two mitigation strategies, the RDI and the HVE, and their effectiveness on coarse $\left(\mathrm{PM}_{10}\right)$, fine $\left(\mathrm{PM}_{2.5}\right)$ and ultrafine $\left(\mathrm{PM}_{0.1}\right)$ dental aerosol particles distribution during a full-crown preparation of anterior teeth (teeth grinding), under controlled conditions in a simulated patient.

\section{Materials and Methods}

\subsection{Dental Simulated Patient}

A dental operating room (DOR), at the School of Dentistry of the Universidad del Valle, was used to perform all the experiments. This DOR consisted in a closed space without windows, equipped with a centralized air-conditioning system and with the following dimensions: $2.4 \mathrm{~m}$ high, $3 \mathrm{~m}$ width and $3 \mathrm{~m}$ large. A dental unit chair with both standard suction (SS) and HVE systems was adapted with a NISSIM Type 1 Dental simulator (NISSIN Dental Products Inc., Kyoto, Japan) (Figure A1) with magnetic attachable full dentate maxillary and mandibular models (NISSIN Dental Products Inc., Kyoto, Japan) to simulate a patient. The mannequin's mouth was fitted internally with latex to simulate the volume of a human oral cavity and the width of the mouth's opening was established and standardized using bilateral dental bite blockers at the second molar level. The average environmental conditions of the DOR were $22{ }^{\circ} \mathrm{C}$ and relative humidity of $65 \%$ during experiments.

\subsection{Particulate Matter Detection and Quantitation}

To detect and quantitate the dental fine $\left(\mathrm{PM}_{2.5}\right)$, the ultrafine $\left(\mathrm{PM}_{0.1}\right)$, as well as the coarse $\left(\mathrm{PM}_{10}\right)$, particles produced during the previously described dental procedure, a laser diffraction technique was implemented, using a specialized device for aerosol testing in a wet environment. The laser device Insitec S (Malvern Panalytical Ltd., Malvern, UK) was in a fixed position, which allowed the detection of dental particles at $11 \mathrm{~cm}$ from the mannequin's upper central incisors (Figure 1a,b). The measurement rate of the particle sizes was 5 per second and the detection size range of the device was $0.1 \mu \mathrm{m}$ to $1000 \mu \mathrm{m}$. The RTSizer 7.4 (Malvern Panalytical Ltd., Malvern, UK) was used to analyse the signals 
generated from the detection of coarse, fine and ultrafine particles during vestibular and palatal preparation of the tooth for a full crown restoration. The retrieved variables aimed to describe the particle-size distribution of interest (between $0.1 \mu \mathrm{m}$ and $10 \mu \mathrm{m}$ ) which included the volume fraction by range of particle sizes. In addition, the 10th, 50th and 90th percentiles of the particle diameter that corresponds to the cumulative undersize distribution by volume for the total particulate matter were calculated ( $\mathrm{Dv}_{10}, \mathrm{Dv}_{50}$ and $\mathrm{Dv}_{90}$, respectively) (ISO Standard $\mathrm{N}^{\circ}$ 13320:2020). Also, the concentration in $\mathrm{mg} / \mathrm{m}^{3}$ for the total particles was measured. In addition, the average size of the dental aerosolized particles below $10 \mu \mathrm{m}$, the Sauter mean diameter $\left(\mathrm{d}_{3,2}\right)$, was determined.

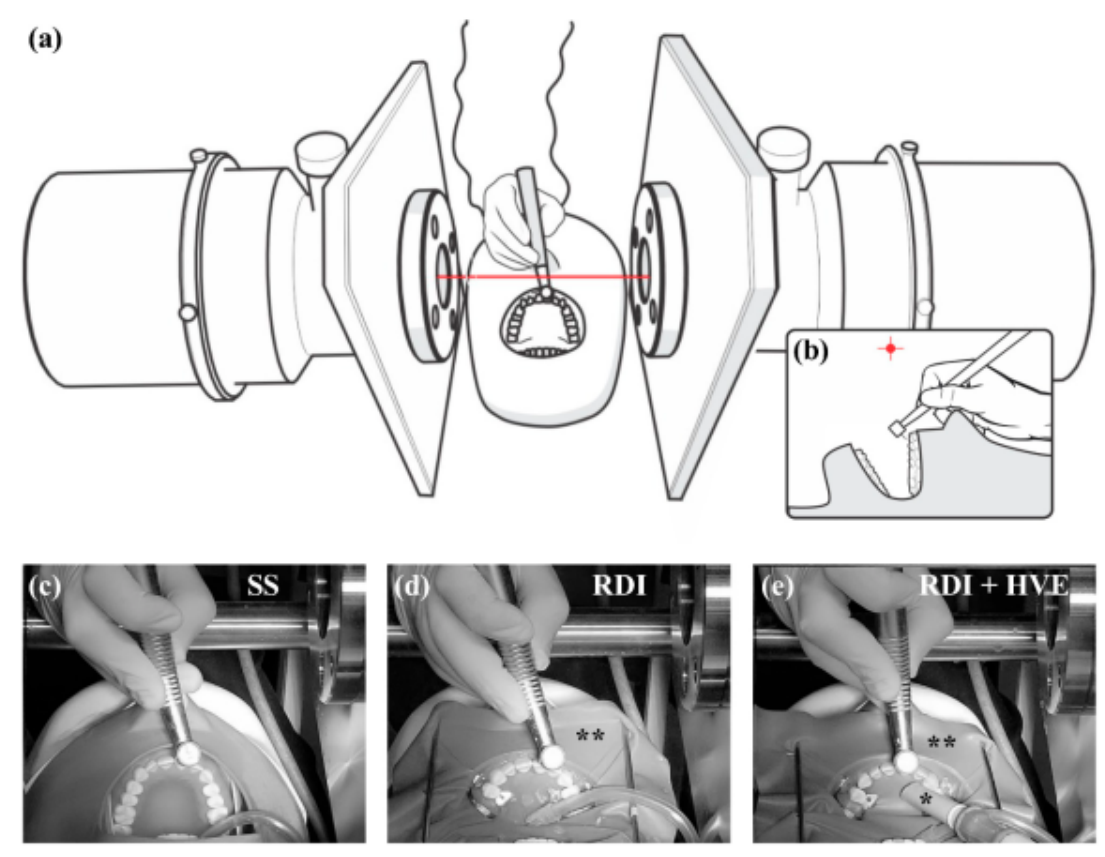

Figure 1. Experimental design using simulated patient and laser diffraction for particle quantitation. (a) Description of the spatial relationship between the mannequin's mouth and laser ray, demonstrating the location of the laser beam of the measurement device (Insitec S; Malvern Panalytical Ltd., Malvern, UK). (b) Scheme sagittal view showing the location of the laser beam (red dot with red cross) from the anterior teeth, at a linear distance of $11 \mathrm{~cm}$. (c-e) Screenshots from the recorder experiments showing the three conditions: (c) standard suction (SS) with a saliva ejector; (d) rubber dam isolation plus standard suction (RDI); (e) rubber dam isolation plus high-volume suction (RDI + HVE) using both the standard suction (saliva ejector) and the high-volume evacuator (straight tip). *: High-volume evacuator's tip; ${ }^{* *}$ : Rubber dam.

\subsection{Dental Isolation and Suction Techniques}

In this first study, the experiments were set up for three different groups (Figure 1c-e). The first group was set up as standard suction (SS), using only a standard saliva ejector (Figure 1c). The second group was set up using rubber dam isolation plus standard suction (RDI) (Figure 1d). The third group included the previously described RDI plus a high-volume evacuator finished in a rigid plastic tip of $12 \mathrm{~cm}$ long and $0.8 \mathrm{~cm}$ of diameter (RDI + HVE) (Figure 1e). For the second and the third groups, the rubber dam isolation was performed using a standardized technique with the perforation guide provided by the manufacturer (Sanctuary Dental Dam Systems@ $@$, Perak, Malaysia) and a metallic frame young's arch. In order to obtain a standardized tension of the rubber dam during the whole experiments, the anterior maxillary and mandibular teeth were isolated up to the first bicuspids, secured with rubber dam clamps (RDCM1 for upper bicuspids and RDCM2 for lower bicuspids; Hu-Friedy Mfg. Co., Chicago, IL, USA), and maintaining the standard saliva ejector over the rubber dam. The HVE system was manually stabilized by the dental assistant (M.d.M.D.-P.) at $15 \mathrm{~mm}$ from the 
palatal side of the tooth of interest (Figure A2). Each experiment was video recorded in high-resolution from a static diagonal front position at $90 \mathrm{~cm}$ from the mouth of the mannequin.

\subsection{Dental Restorative Procedures}

To simulate grinding dental procedures, a standardized protocol of anterior teeth full-crown preparation was performed by an experienced prosthodontist clinician (D.G.). The sequence for full-crown preparation started with the vestibular side, followed by interproximal sides (mesial first, then distal), palatal side, and finished with the incisal part, for a complete anterior tooth preparation that lasted $6 \mathrm{~min}$ (standardized total time for full crown preparation in each experiment). An EXTRAtorque 605C high-speed handpiece (with press button, Borden 2-hole connection, triple spray and rotation between 280,000-380,000 rpm) (KaVo Dental, Charlotte, NC, USA) with current water coolant to prepare acrylic teeth were used (NISSIN Dental Products Inc., Kyoto, Japan). The protocol was performed with a diamond coated (medium size grain between 64-126 $\mu \mathrm{m}$ ) tapered chamfer dental burr with round end (reference 852, 016) for universal teeth grinding procedures (Hager and Meisinger GmbH, Neuss, Germany). The dental burr was replaced for a new one for the different settings and upper central incisors were replaced for each experiment.

\subsection{Statistical Analysis}

The experiments for each condition were performed in triplicate. Results are shown as mean \pm standard error of the mean (SEM). For the statistical analysis, a comparison of the quantitative variables between each RDI condition and the SS set up, and between sides (vestibular versus palatal), was performed using the Mann-Whitney test for non-normally distributed data. A logarithmic scale $\left(\log _{10}\right)$ between $0.1 \mu \mathrm{m}$ and $10 \mu \mathrm{m}$ was implemented to plot the curve of particle-size distribution (based on the volume fraction) for each condition. The software GraphPad Prism version 8.4.3 for Windows (GraphPad Software, San Diego, CA, USA, www.graphpad.com) was used to perform the statistical analysis and to plot the graphs. A significance level of 0.05 was established for differences among the described variables.

\section{Results}

\subsection{Ultrafine Dental Aerosol Particles Are Generated during Full-Crown Teeth Preparation}

To determine the behaviour of AGP in each simulated condition (SS, standard suction; RDI, rubber dam isolation; RDI + HVE, rubber dam isolation plus high-volume evacuator), a volume frequency distribution in the range $0.1-10 \mu \mathrm{m}$ was generated for both vestibular and palatal sides (Figure 2a,b, respectively). Using only standard suction, the curve showed a displacement to the left, in the range below $1 \mu \mathrm{m}$ in size, in both vestibular and palatal sides (Figure 2a,b). In contrast, in the RDI group, the curve was displaced to the middle and to the right, in the range between 1-10 $\mu \mathrm{m}$, for both sides. For the RDI + HVE group, the location of HVE in the palatal side was consistent with less particle generation whereas in the vestibular side the curve exhibited two peaks: below $1 \mu \mathrm{m}$ and over $7 \mu \mathrm{m}$ (Figure 2a,b). During full-crown preparation, in the SS group, no $\mathrm{PM}_{2.5}$ was detected in the vestibular side or in the palatal side, and no significant difference was found in the vestibular side between $\mathrm{PM}_{0.1}$ and $\mathrm{PM}_{10}$ (Table 1). In contrast, there was a significant difference between $\mathrm{PM}_{0.1}$ and $\mathrm{PM}_{10}$ in the palatal side for the SS group $(p<0.05)$. Only one of three experiments detected a small percentage of fine particles $\left(\mathrm{PM}_{2.5}\right)$ in both vestibular and palatal sides of the RDI group (Figure 2a,b, Table 1). No significant difference was found in the volume fraction for $\mathrm{PM}_{0.1}, \mathrm{PM}_{2.5}$ and $\mathrm{PM}_{10}$ between vestibular and palatal sides $(p>0.05)$. 
(a)

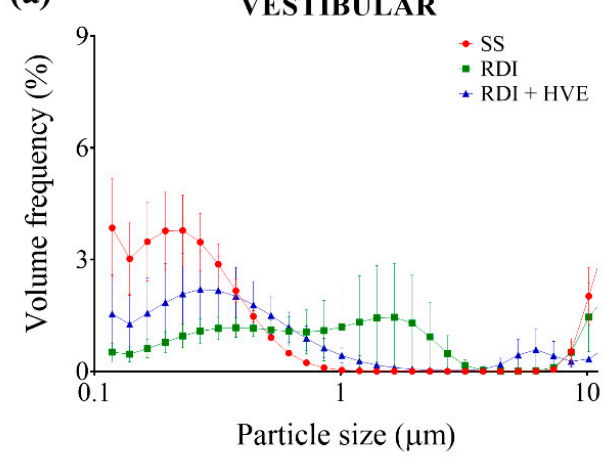

(b)

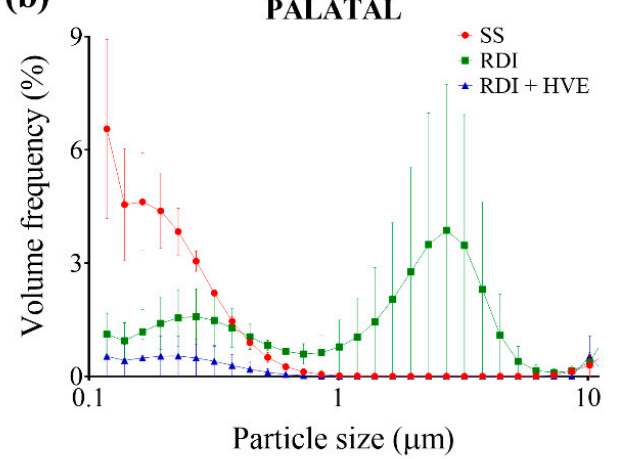

Figure 2. Curve distribution of volume fraction of the dental aerosolized particles under $10 \mu \mathrm{m}$. (a) The vestibular side shows an increased volume fraction for particles below $0.1 \mu \mathrm{m}$ for the SS group, when compared to the RDI and RDI + HVE groups. (b) In the palatal side, the volume fraction distribution follows a similar pattern seen in (a), except for the RDI + HVE group. Results are shown as mean \pm standard error of the mean (SEM); $n=3$. Abbreviations: SS, standard suction; RDI, rubber dam isolation; HVE, high-volume evacuator. $\mathrm{X}$ axis (Particle size) is $\log _{10}$ scaled.

Table 1. Volume fraction of ultrafine $\left(\mathrm{PM}_{0.1}\right)$, fine $\left(\mathrm{PM}_{2.5}\right)$, and coarse $\left(\mathrm{PM}_{10}\right)$ dental aerosol particles.

\begin{tabular}{ccccc}
\hline \multirow{2}{*}{ Side } & \multirow{2}{*}{$\begin{array}{c}\text { Particulate } \\
\text { Matter Size }\end{array}$} & \multicolumn{3}{c}{ Volume Fraction (\%) by Group } \\
\cline { 3 - 5 } & & SS & RDI & RDI + HVE \\
\hline \multirow{3}{*}{ Vestibular } & $\mathrm{PM}_{0.1}$ & $3.85 \pm 1.33$ & {$[0.52 \pm 0.25]^{*}$} & $1.54 \pm 1.06$ \\
& $\mathrm{PM}_{2.5}$ & $0.00 \pm 0.00$ & $0.93 \pm 0.93$ & $0.03 \pm 0.01$ \\
& $\mathrm{PM}_{10}$ & $2.02 \pm 0.77$ & $1.45 \pm 0.92$ & {$[0.33 \pm 0.04]^{*}$} \\
\hline \multirow{3}{*}{ Palatal } & $\mathrm{PM}_{0.1}$ & $6.56 \pm 2.37$ & {$[1.11 \pm 0.56]^{*}$} & {$[0.53 \pm 0.53]^{*}$} \\
& $\mathrm{PM}_{2.5}$ & $0.00 \pm 0.00$ & $3.49 \pm 3.49$ & $0.00 \pm 0.00$ \\
& $\mathrm{PM}_{10}$ & $0.29 \pm 0.29$ & $0.37 \pm 0.25$ & $0.53 \pm 0.53$ \\
\hline
\end{tabular}

Comparison between groups shows a significant production of ultrafine particles during full-crown anterior teeth preparation. RDI and RDI + HVE strategies reduce these ultrafine particles in both vestibular side and palatal side. No difference was found for any parameter between vestibular side and palatal side. Results are shown as Mean \pm SEM; $n=3$. The brackets and the asterisk $\left({ }^{*}\right)$ mean statistical difference when compared RDI and RDI + HVE to the SS group $(p<0.05)$. Abbreviations: PM, particulate matter; SS, standard suction; RDI, rubber dam isolation; HVE, high-volume evacuator.

\subsection{Rubber Dam Isolation and High-Volume Suction Reduce the Volume Fraction of Ultrafine Dental Aerosol Particles}

To determine the effectiveness of mitigation strategies to reduce dental aerosol particles, a comparison among SS, RDI and RDI + HVE groups was performed. In comparison to the SS group, a significant reduction of the ultrafine particles $\left(\mathrm{PM}_{0.1}\right)$ was found when the RDI was implemented $(p<0.05)$ but not for the use of RDI + HVE in the vestibular side (Figure 2a, Table 1). In the same side, a significant reduction of the coarse particles $\left(\mathrm{PM}_{10}\right)$ was achieved with the use of both rubber dam isolation and high-volume suction $(p<0.05)$ when compared to the SS group (Figure 2a, Table 1). On the other hand, in the palatal side, the ultrafine particles $\left(\mathrm{PM}_{0.1}\right)$ were significantly reduced with the use of RDI alone or combined with HVE (RDI and RDI + HVE groups) $(p<0.05)$ (Figure 2b, Table 1).

\subsection{Rubber Dam Isolation and High-Volume Suction Reduce the Concentration of Dental Aerosol Particles}

To determine the percentile distribution of dental aerosolized particles generated during the full-crown anterior teeth preparation, $\mathrm{Dv}_{10}, \mathrm{Dv}_{50}$ and $\mathrm{Dv}_{90}$ were calculated. After comparison, $\mathrm{Dv}_{10}$, $\mathrm{Dv}_{50}$ and $\mathrm{Dv}_{90}$ of the SS group were significantly lower $(p<0.05)$ than the RDI group in both vestibular side and palatal side (Figure $3 \mathrm{a}, \mathrm{b})$. $\mathrm{Dv}_{10}$ and $\mathrm{Dv}_{90}$ of the RDI group was significantly higher than the RDI + HVE group in the palatal side $(p<0.05)$ (Figure $3 b)$. In addition, $\mathrm{Dv}_{50}$ and $\mathrm{Dv}_{90}$ of the SS group were significantly lower than RDI + HVE group in the vestibular side $(p<0.05)$ but no differences were found in the palatal side (Figure 3a,b). 
(a)

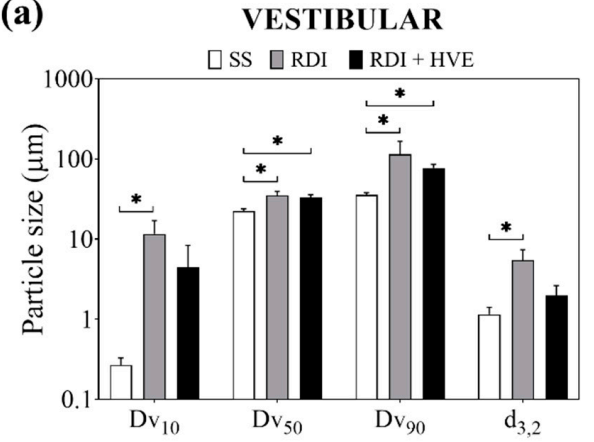

(b)

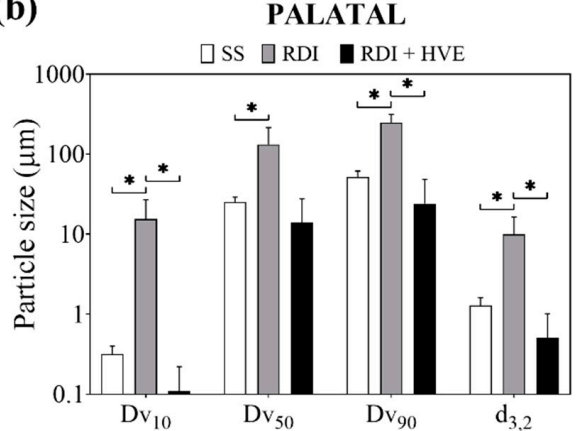

(c)

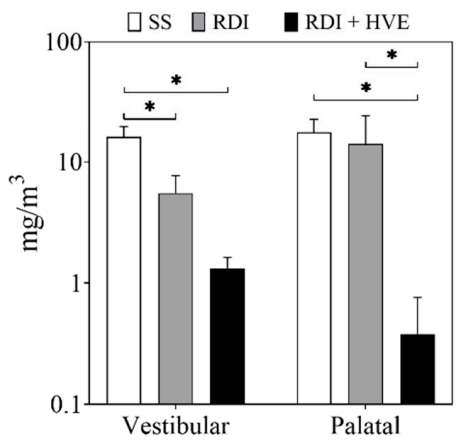

Figure 3. Rubber dam isolation and high-volume suction reduce dental aerosol particles. The distribution by volume (Dv) parameters for percentiles 10,50 and 90 are shown for the vestibular side in plot (a) and the palatal side in plot (b). For these three percentiles, there is an increase in the average size of the particles based on the volume percent when the RDI is implemented. A significant increase in the $d_{3,2}$ (the average size of particles below $10 \mu \mathrm{m}$ ) is observed with the use of the RDI, but no effect is detected in the RDI + HVE group, when compared with the SS group. (c) The RDI and the RDI + HVE strategies reduce the concentration of aerosol-generating procedures (AGPs) in the vestibular side when compared with the SS group. In contrast, the RDI + HVE reduce this parameter when compared with both the SS group and the RDI group, in the palatal side. Results are shown as mean \pm SEM; $n=3$; * $p<0.05$. Abbreviations: SS, standard suction; RDI, rubber dam isolation; HVE, high-volume evacuator. The $Y$ axis of $(\mathbf{a}),(\mathbf{b})$ and $(\mathbf{c})$ is $\log _{10}$ scaled.

To determine the effect of the mitigation strategies on the average size of the particles below $10 \mu \mathrm{m}$ for each condition, the Sauter mean diameter $\left(\mathrm{d}_{3,2}\right)$ was determined. For the SS group, the $d_{3,2}$ was significantly lower than the RDI group in both vestibular side and palatal side $(p<0.05)$ whereas the $d_{3,2}$ of the RDI group was significantly higher than the RDI + HVE group in the palatal side (Figure $3 \mathrm{a}, \mathrm{b}$ ). For the Dv parameters, no difference was found between vestibular side and palatal side in each group.

Both mitigation strategies, RDI and RDI + HVE, significantly reduced the concentration of aerosol particles in the vestibular side, when compared with the SS group $(p<0.05)$ (Figure 3c). In the palatal side, however, only the RDI + HVE showed effectiveness at reducing dental aerosol particles, compared to the SS and the RDI groups $(p<0.05)$ (Figure 3c). No difference was found between vestibular side and palatal side for any group.

\section{Discussion}

Our study demonstrates that the location of the tip of the high-volume evacuator, facing the aerosol-generating procedure side, and combined with rubber dam isolation, significantly reduce the volume fraction of the ultrafine particles $\left(\mathrm{PM}_{0.1}\right.$ or nanoparticles). In addition, the total concentration of aerosol particles produced during the drilling of resin-made teeth under controlled conditions was also significantly reduced in both vestibular and palatal sides using RDI + HVE. The ultrafine particles 
here detected corresponded to the highest proportion among aerosol dental particles in the hazardous range (aerodynamic diameter below $10 \mu \mathrm{m}$ ) [21,26,28] when standard suction is implemented. Also, the use of rubber dam isolation combined with standard suction (RDI group) increased the average size of the dental aerosol particles, when compared with standard suction alone (SS). Moreover, the rubber dam isolation combined with high-volume suction effectively reduced the volume fraction of ultrafine particles in both vestibular side and palatal side. However, a significant reduction of total dental aerosol particles was only obtained in the palatal side using RDI + HVE when compared with SS and RDI conditions. This result suggests that the location of the high-volume evacuator based on the drilling side should be considered in aerosol mitigation strategies.

Simulation training is an effective method to test under safe conditions the response and the performance of health care personnel during AGPs in highly infectious disease context [29]. This dental simulator unit is a fast-response strategy to study AGPs in a dental office under controlled and patient-free conditions. Although this experimental setting is accurate for the study, it cannot replace real crown preparations, plus the use of artificial teeth for gridding might be different to that with natural teeth. Other clear limitation is the equipment use which require to be fixed, secure, and close to the mouth for proper measurement. In this context, the laser beam is not flexible due to the limited spatial range for aerosol quantitation. Therefore, this result should be used for comparisons with experiments carried out under similar controlled conditions, considering limitations such as the lack of microbial biofilms that bind to natural teeth, caries, oral and periodontal mucosa, quantity and quality of saliva and blood presence (which may affect the particle size of the dental aerosol particles) and other physiological confounding factors that may affect the behaviour of AGPs such as breathing and previous oral hygiene or previous rinse use within a real patient [30-32].

This study demonstrated that AGPs after teeth drilling are polydisperse by using a laser diffraction technique, with the highest proportion of ultrafine particles $\left(\mathrm{PM}_{0.1}\right)$ in the hazardous particle size range $\left(\mathrm{PM}_{10}\right)$. Interestingly, the particle fraction between $\mathrm{PM}_{0.3-0.5}$ correlated with tooth drilling procedures in a real dental operating room, with no contribution of the particulate matter over $1 \mu \mathrm{m}$ [17]. This is consistent with our findings, in which aerosol particles were poorly or not detected over $1 \mu \mathrm{m}$ during artificial teeth drilling using standard suction in both vestibular and palatal sides. Nevertheless, the relative humidity was reported $40 \%$ [17], in contrast with our settings (average relative humidity: $65 \%)$. With a higher relative humidity $(70 \%)$, another study reported similar findings regarding the increase of ultrafine particles during teeth drilling and grinding [33].

From the biomaterial point of view, we suggest that artificial teeth are a useful tool to reproduce dental tissues. Similarly, an experimental study that drilled and grinded natural teeth detected the highest proportion of dental aerosol particles in the $\mathrm{PM}_{1}$ fraction, with no significant effect of the vacuum system on the ultrafine particles concentration [16]. The opposite effect was found in our study using high-volume suction, with a significant reduction of the volume fraction of the ultrafine particles in the palatal side (the same side where the tip of the volume evacuator was located). In contrast, this significant reduction in the RDI + HVE group was not observed in the vestibular side (Table 1). This can be explained by the fact that the tip of the high-volume evacuator was not able to suction properly these ultrafine particles, in part because of its location (palatal side) and due to the physical barrier of the tooth.

Currently RDI is highly recommended, even during restorative procedures to reduce infection risk [3,4]. When measured at one and two meters from the patient's mouth, the number of colony-forming units (CFUs) is reduced in two trials during restorative procedures with high-speed handpiece and RDI in children $[34,35]$. In contrast, when CFUs were measured in several points of the clinician's head, these were significantly increased when using rubber dam isolation versus control during restorative procedures in adults [14]. Aerosol particle sizes were not reported in these studies. In our study, the $\mathrm{Dv}_{10}, \mathrm{Dv}_{50}, \mathrm{Dv}_{90}$ and the $\mathrm{d}_{3,2}$ of RDI group were significantly increased when compared with no rubber dam isolation (SS group) in both vestibular side and palatal side. This result may be explained by the fact that the study that took CFU measurements closer to the mouth of the patient [14] found an 
increase in this parameter, since larger particles may reach closer surfaces (e.g., clinician's head) but failed to reach longer distances (i.e., one to two meters from the patient's mouth).

Because of the lack of previous published studies on the methods implemented here, we were not able to perform a sample size calculation. However, the first results reported here are the basis for the experimental design, including statistical analysis and sample size calculation, of further and larger studies. Therefore, a triplicate experiment per condition was implemented in order to determine the feasibility of the experimental settings when analysing dental aerosol particles using laser diffraction. Taken together, our preliminary results support the effectiveness of the rubber dam isolation combined with high-volume suction to reduce the dental aerosol particles, although not always significantly and not for all particle sizes. Interestingly, the use of rubber dam isolation (with no HVE) reduces the ultrafine particles but increase the $\mathrm{Dv}_{10-50-90}$ and the $\mathrm{d}_{3,2}$ of total aerosol particles, which may increase their precipitation rate but also the surface of contamination in areas close to the patient's mouth. Further studies regarding the potential of infection of dental aerosol particles in the submicron range (under $\mathrm{PM}_{10}$ ) are necessary. RDI is not possible for some procedures like dental surgery or dental hygiene. The results here reported represent a promising tool not only for the control of dental aerosol but also to understand the behaviour of airborne nanoparticles and mitigation strategies [36].

Author Contributions: Conceptualization, J.B.-M., A.G., G.S., M.d.M.D.-P., D.G., J.V. and A.C.; Data curation, J.B.-M., A.G., G.S., M.d.M.D.-P. and D.G.; Formal analysis, J.B.-M. and A.G.; Methodology, J.B.-M., A.G. and G.S.; Writing —original draft, J.B.-M., A.G., G.S., M.d.M.D.-P. and D.G.; Writing—review and editing, J.B.-M., A.G., J.V. and A.C. All authors have read and agreed to the published version of the manuscript.

Funding: This research received no external funding.

Acknowledgments: We are grateful to Diego Nieto, professional technician at the School of Dentistry (Universidad del Valle, Colombia), for assisting with the experimental set up of the simulated patient (mannequin) on the dental chair and the management of the main operative system that provided air/water/electrical input to the dental operating room during each experiment. We also thank Paula Sandoval, professional administrative at the School of Dentistry (Universidad del Valle, Colombia), for contributing with the experimental schedule and the access to the dental operating room during the COVID-19 pandemic outbreak.

Conflicts of Interest: The authors declare no conflict of interest.

\section{Appendix A}

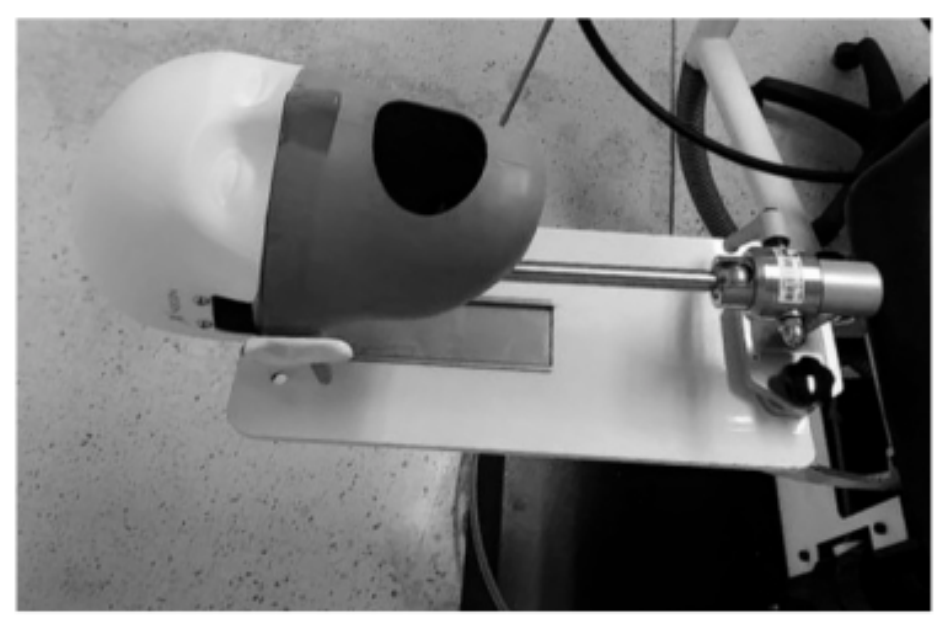

Figure A1. NISSIM Type 1 Dental simulator (NISSIN Dental Products Inc., Kyoto, Japan) attached to a dental unit chair with both standard suction and high-volume suction systems [these elements are not shown in the figure]. 


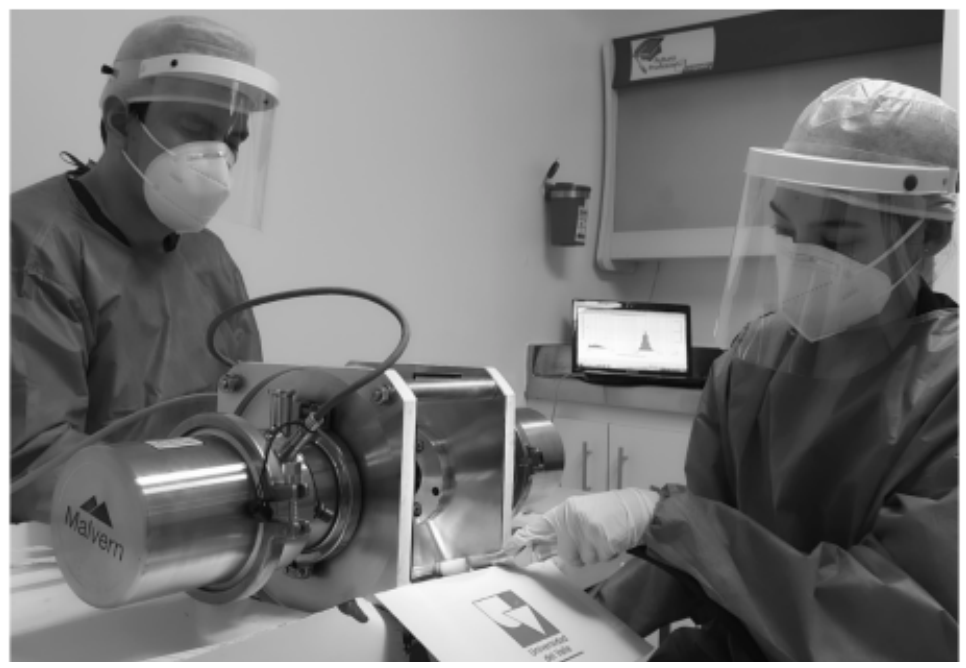

Figure A2. The experimental setting with the clinician in the left side of the image, the measurement device, Insitec S (Malvern Panalytical Ltd., Malvern, UK) in the middle, the dental assistant holding the high-volume evacuator in the right and the real-time analytical computer equipment in the background.

\section{References}

1. Coulthard, P. Dentistry and coronavirus (COVID-19)—moral decision-making. Br. Dent. J. 2020, 228, 503-505. [CrossRef] [PubMed]

2. Zemouri, C.; Volgenant, C.M.C.; Buijs, M.J.; Crielaard, W.; Rosema, N.A.M.; Brandt, B.W.; Laheij, A.; De Soet, J.J. Dental aerosols: Microbial composition and spatial distribution. J. Oral Microbiol. 2020, 12, 1762040. [CrossRef] [PubMed]

3. Ather, A.; Patel, B.; Ruparel, N.B.; Diogenes, A.; Hargreaves, K.M. Coronavirus Disease 19 (COVID-19): Implications for Clinical Dental Care. J. Endod. 2020, 46, 584-595. [CrossRef] [PubMed]

4. Clarkson, J.R.C.; Richards, D.; Robertson, C.; Aceves-Martins, M.; On behalf of the CoDER Working Group. Aerosol Generating Procedures and their Mitigation in International Dental Guidance Documents-A Rapid Review. 2020. Available online: https://oralhealth.cochrane.org/news/aerosol-generating-procedures-andtheir-mitigation-international-guidance-documents (accessed on 30 July 2020).

5. To, K.K.; Tsang, O.T.; Leung, W.S.; Tam, A.R.; Wu, T.C.; Lung, D.C.; Yip, C.C.; Cai, J.P.; Chan, J.M.; Chik, T.S.; et al. Temporal profiles of viral load in posterior oropharyngeal saliva samples and serum antibody responses during infection by SARS-CoV-2: An observational cohort study. Lancet Infect. Dis. 2020, 20, 565-574. [CrossRef]

6. Chen, J.H.; Yip, C.C.; Poon, R.W.; Chan, K.H.; Cheng, V.C.; Hung, I.F.; Chan, J.F.; Yuen, K.Y.; To, K.K. Evaluating the use of posterior oropharyngeal saliva in a point-of-care assay for the detection of SARS-CoV-2. Emerg. Microbes Infect 2020, 9, 1356-1359. [CrossRef]

7. Peng, X.; Xu, X.; Li, Y.; Cheng, L.; Zhou, X.; Ren, B. Transmission routes of 2019-nCoV and controls in dental practice. Int. J. Oral Sci. 2020, 12, 9. [CrossRef]

8. Patini, R. How to Face the Post-SARS-CoV-2 Outbreak Era in Private Dental Practice: Current Evidence for Avoiding Cross-infections. J. Int. Soc. Prev. Community Dent. 2020, 10, 237-239. [CrossRef]

9. WHO Global. Considerations for the Provision of Essential Oral Health Services in the Context Of COVID-19. Available online: https://www.who.int/publications/i/item/who-2019-nCoV-oral-health-2020.1 (accessed on 11 August 2020).

10. Meng, L.; Hua, F.; Bian, Z. Coronavirus Disease 2019 (COVID-19): Emerging and Future Challenges for Dental and Oral Medicine. J. Dent. Res. 2020, 99, 481-487. [CrossRef]

11. Izzetti, R.; Nisi, M.; Gabriele, M.; Graziani, F. COVID-19 Transmission in Dental Practice: Brief Review of Preventive Measures in Italy. J. Dent. Res. 2020, 99, 1030-1038. [CrossRef]

12. Ge, Z.Y.; Yang, L.M.; Xia, J.J.; Fu, X.H.; Zhang, Y.Z. Possible aerosol transmission of COVID-19 and special precautions in dentistry. J. Zhejiang Univ. Sci. B 2020, 21, 361-368. [CrossRef] 
13. Koletsi, D.; Belibasakis, G.N.; Eliades, T. Interventions to Reduce Aerosolized Microbes in Dental Practice: A Systematic Review with Network Meta-analysis of Randomized Controlled Trials. J. Dent. Res. 2020. [CrossRef] [PubMed]

14. Al-Amad, S.H.; Awad, M.A.; Edher, F.M.; Shahramian, K.; Omran, T.A. The effect of rubber dam on atmospheric bacterial aerosols during restorative dentistry. J. Infect. Public Health 2017, 10, 195-200. [CrossRef] [PubMed]

15. Holloman, J.L.; Mauriello, S.M.; Pimenta, L.; Arnold, R.R. Comparison of suction device with saliva ejector for aerosol and spatter reduction during ultrasonic scaling. J. Am. Dent. Assoc. 2015, 146, 27-33. [CrossRef] [PubMed]

16. Liu, M.H.; Chen, C.T.; Chuang, L.C.; Lin, W.M.; Wan, G.H. Removal efficiency of central vacuum system and protective masks to suspended particles from dental treatment. PLoS ONE 2019, 14, e0225644. [CrossRef] [PubMed]

17. Sotiriou, M.; Ferguson, S.F.; Davey, M.; Wolfson, J.M.; Demokritou, P.; Lawrence, J.; Sax, S.N.; Koutrakis, P. Measurement of particle concentrations in a dental office. Environ. Monit. Assess. 2008, 137, 351-361. [CrossRef]

18. Wilson, W.E.; Suh, H.H. Fine particles and coarse particles: Concentration relationships relevant to epidemiologic studies. J. Air. Waste Manag. Assoc. 1997, 47, 1238-1249. [CrossRef]

19. Pope, C.A., 3rd; Bhatnagar, A.; McCracken, J.P.; Abplanalp, W.; Conklin, D.J.; O’Toole, T. Exposure to Fine Particulate Air Pollution Is Associated with Endothelial Injury and Systemic Inflammation. Circ. Res. 2016, 119, 1204-1214. [CrossRef]

20. Chang, X.; Zhou, L.; Tang, M.; Wang, B. Association of fine particles with respiratory disease mortality: A meta-analysis. Arch. Environ. Occup. Health 2015, 70, 98-101. [CrossRef]

21. Yang, Y.; Ruan, Z.; Wang, X.; Yang, Y.; Mason, T.G.; Lin, H.; Tian, L. Short-term and long-term exposures to fine particulate matter constituents and health: A systematic review and meta-analysis. Environ. Pollut. 2019, 247, 874-882. [CrossRef]

22. Zoran, M.A.; Savastru, R.S.; Savastru, D.M.; Tautan, M.N. Assessing the relationship between surface levels of PM2.5 and PM10 particulate matter impact on COVID-19 in Milan, Italy. Sci. Total Environ. 2020, 738, 139825. [CrossRef]

23. Zhu, Y.; Xie, J.; Huang, F.; Cao, L. Association between short-term exposure to air pollution and COVID-19 infection: Evidence from China. Sci. Total Environ. 2020, 727, 138704. [CrossRef]

24. Lindsley, W.G.; Blachere, F.M.; Thewlis, R.E.; Vishnu, A.; Davis, K.A.; Cao, G.; Palmer, J.E.; Clark, K.E.; Fisher, M.A.; Khakoo, R.; et al. Measurements of airborne influenza virus in aerosol particles from human coughs. PLoS ONE 2010, 5, e15100. [CrossRef]

25. Liu, Y.; Ning, Z.; Chen, Y.; Guo, M.; Liu, Y.; Gali, N.K.; Sun, L.; Duan, Y.; Cai, J.; Westerdahl, D.; et al. Aerodynamic analysis of SARS-CoV-2 in two Wuhan hospitals. Nature 2020, 582, 557-560. [CrossRef] [PubMed]

26. Schraufnagel, D.E. The health effects of ultrafine particles. Exp. Mol. Med. 2020, 52, 311-317. [CrossRef] [PubMed]

27. Harrel, S.K.; Molinari, J. Aerosols and splatter in dentistry: A brief review of the literature and infection control implications. J. Am. Dent. Assoc. 2004, 135, 429-437. [CrossRef] [PubMed]

28. Fennelly, K.P. Particle sizes of infectious aerosols: Implications for infection control. Lancet. Respir. Med. 2020, 8, 914-924. [CrossRef]

29. Grillet, G.; Marjanovic, N.; Diverrez, J.M.; Tattevin, P.; Tadie, J.M.; L’Her, E. Intensive care medical procedures are more complicated, more stressful, and less comfortable with Ebola personal protective equipment: A simulation study. J. Infect. 2015, 71, 703-706. [CrossRef]

30. Scheuch, G. Breathing Is Enough: For the Spread of Influenza Virus and SARS-CoV-2 by Breathing Only. J. Aerosol. Med. Pulm. Drug Deliv. 2020, 33, 230-234. [CrossRef]

31. Wolff, D.; Frese, C.; Schoilew, K.; Dalpke, A.; Wolff, B.; Boutin, S. Amplicon-based microbiome study highlights the loss of diversity and the establishment of a set of species in patients with dentin caries. PLoS ONE 2019, 14, e0219714. [CrossRef]

32. Aas, J.A.; Griffen, A.L.; Dardis, S.R.; Lee, A.M.; Olsen, I.; Dewhirst, F.E.; Leys, E.J.; Paster, B.J. Bacteria of dental caries in primary and permanent teeth in children and young adults. J. Clin. Microbiol. 2008, 46, 1407-1417. [CrossRef] 
33. Polednik, B. Aerosol and bioaerosol particles in a dental office. Environ. Res. 2014, 134, 405-409. [CrossRef] [PubMed]

34. Tag El Din, A.M.; Ghoname, N.A.H. Efficacy of rubber dam isolation as an infection control procedure in paediatric dentistry. East. Mediterr. Health J. 1997, 3, 530-539.

35. Samaranayake, L.P.; Reid, J.; Evans, D. The efficacy of rubber dam isolation in reducing atmospheric bacterial contamination. ASDC J. Dent. Child 1989, 56, 442-444. [PubMed]

36. Chenthamara, D.; Subramaniam, S.; Ramakrishnan, S.G.; Krishnaswamy, S.; Essa, M.M.; Lin, F.H.; Qoronfleh, M.W. Therapeutic efficacy of nanoparticles and routes of administration. Biomater. Res. 2019, 23, 20. [CrossRef]

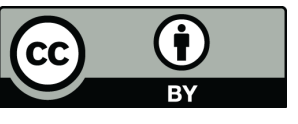

(C) 2020 by the authors. Licensee MDPI, Basel, Switzerland. This article is an open access article distributed under the terms and conditions of the Creative Commons Attribution (CC BY) license (http://creativecommons.org/licenses/by/4.0/). 